\title{
The JAEL System: A Joystick-Controlled Appliance for Exact Laboratory Procedures
}

\section{Alfredo Gilbert*}

Torre MédicaMetropolitana, Tampico \#8 Col, Roma, México

\begin{abstract}
Set-up models are used for a wide variety of dental procedures, from bridge and crown elaboration, maxillofacial surgery planning and for the indirect bonding of lingual brackets. The first step in the construction of a set-up model is the sectioning of the malocclusion model. Manually sectioning malocclusion models is a laborious, often imprecise process than generates a large amount of dust. In this article we present the JAEL system-a joystick-controlled, remote-operated machine which quickly, precisely and cleanly sections malocclusion models for use in procedures such as prosthetic appliances, maxillofacial surgical predictions and the indirect bonding of lingual brackets.
\end{abstract}

Keywords: Orthodontics; Dental Lab; Prothesis; Surgery; Lab devices; Setup; Lingual Orthodontics

\section{Introduction}

The sectioning of dental models is an important part of a variety of medical procedures, including orthognathic surgery planning [1], the indirect bonding of lingual orthodontic brackets [2] or the design of many dental reconstructions. In surgical cases, set-up models are used to determine the movements necessary to achieve a stable, harmonic and functional occlusion. Models are used both to determine the desired surgical outcome [3] and to make the splints which are used to obtain and then set the desired occlusal positions. Set-up models also perform a didactic function, allowing a comparison of the anticipated result with the actual post-operation result. In orthodontic cases the set-up should be constructed during the diagnostic phase. The set-up provides the opportunity to simulate treatment results before treatment has begun, allows for better decision making with regard to extractions, interproximal stripping and the type of anchorage to use, and allows the orthodontist to assess the limitations of the case. The set-up facilitates the creation of a good final occlusal relationship and allows the orthodontist to visualize the final position of each tooth. This is particularly important in the case of tooth size discrepancies. The fabrication of resin or metal bracket bases for the indirect bonding of lingual orthodontic brackets is only possible using a set-up model [4]. In lingual orthodontics, the set-up model is complemented by an ideal arch wire, generally of $0.18 \times 0.25$ stainless steel, to which the brackets are attached. This arch wire, upon being fitted to the set-up model, permits the elaboration of prescription brackets, thus avoiding the need for complicated second- or thirdorder bends of the arch wire and permitting the use of the straight-wire technique [5].

In the manufacturing of crown and bridges prosthesis, the set-up of the models is imperative in order to get the best possible adjustment of the devices. It is simply impossible to obtain good results without the splitting of individuals at the time of lab working. The technician must have a perfect access to all the surfaces of the teeth and an excellent form to reviewing the contact point of the reconstructions he is doing. It has been suggested that the use of photocopies, photographs and holograms, and various digital imaging techniques may simplify the process of recording measurements for diagnosis and treatment planning [6]; however these methods are themselves not free from error $[7,8]$. It is important to note that, while computed tomography (CT) may provide information useful for diagnosis or treatment planning [9], it does not completely eliminate the need for physical models.
We note that the manner in which a malocclusion model is sectioned depends on the use to which the set-up model will be put; in particular, if a set-up model is to be used for diagnostic purposes, to demonstrate a treatment outcome to a patient, or for the indirect bonding of lingual brackets, then the malocclusion model must be sectioned into individual teeth, and each tooth must be further sectioned in order to provide space for repositioning [10]. Manually sectioning a dental model is laborious and time-consuming, and the result may not be as precise as desired. The significant quantity of dust generated by the procedure may produce an unpleasant work environment and represent a health risk to those exposed.The device presented in this article, the JAEL system, allows the technician to section malocclusion models into large segments or individual teeth. It is hoped that use of the system will make the sectioning of malocclusion models easier, safer and more precise, and reduce the time needed to construct set-up models.

\section{The JAEL System}

The JAEL system consists of a stable base which supports a movable horizontal platform on which the malocclusion model to be sectioned is placed. A series of rods attached to the base supports a holder into which is placed a dental bur angled vertically downward. The platform on which the model is placed is able to move forwards and backwards relative to the base; the dental bur holder is able to move left and right and up and down relative to the base. One may think of an imaginary box located on the movable platform which contains the model to be sectioned. The bur is able to reach any point inside this box, including any point on the surface or in the interior of the model. The base, the movable platform and the dental bur and its supporting structure are shown in Figures 1a and $1 \mathrm{~b}$.

The position of the bur is described by means of a Cartesian

*Corresponding author: Alfredo Gilbert, Torre MédicaMetropolitana, Tampico \#8 Col, Roma, MéxicoTel: 55-5211-8718; E-mail: alfredogilbert@gmail.com

Received November 05, 2014; Accepted November 23, 2014; Published January 05, 2015

Citation: Gilbert A (2015) The JAEL System: A Joystick-Controlled Appliance for Exact Laboratory Procedures. J Comput Sci Syst Biol 8: 034-036. doi:10.4172/ jcsb. 1000167

Copyright: (c) 2015 Gilbert A. This is an open-access article distributed under the terms of the Creative Commons Attribution License, which permits unrestricted use, distribution, and reproduction in any medium, provided the original author and source are credited. 


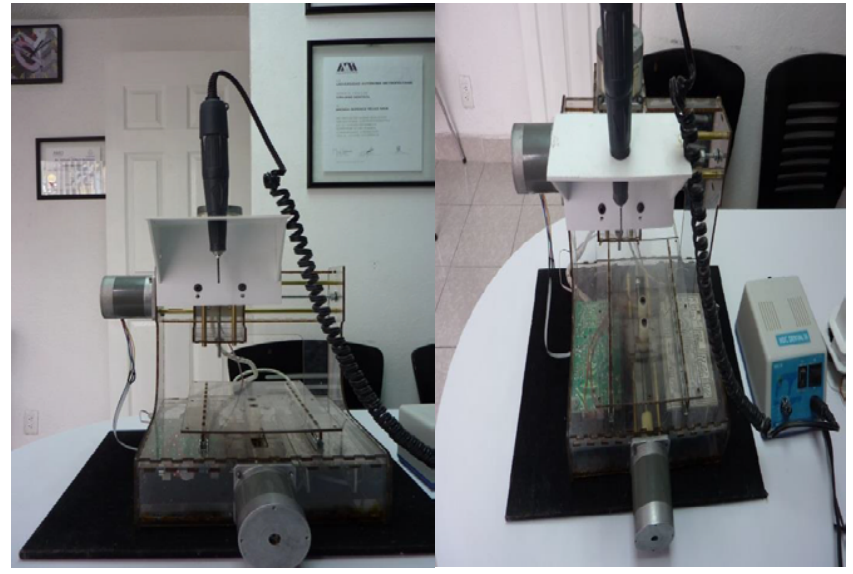

Figure 1a and 1b: Two different views of the base, the movable platform, the dental bur holder (in white) and its supporting structure, and the dental bur. The movable platform moves forward and backward with respect to the base; the dental bur holder and the dental bur move left and right and up and down with respect to the base.z

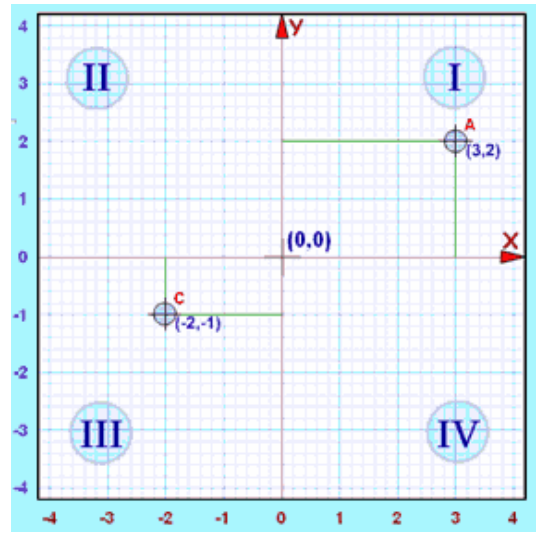

Figure 2: A two-dimensional Cartesian coordinate system with the points $(3,2)$ and $(-2,-1)$ and the four quadrants labelled.

coordinate system [11]. In two dimensions, two straight, perpendicular, lines, the $\mathrm{X}$ and $\mathrm{Y}$ axes, form the basis of the Cartesian coordinate system. By convention, the $\mathrm{X}$ axis is horizontal and the $\mathrm{Y}$ axis vertical. The point of intersection of the two axes defines the origin of the system (O). Any point in the plane may be identified by a pair of numbers describing the horizontal and the vertical distances of the point from the origin. For example, if one begins at the origin, then the point $(3,2)$ is found by moving three units to the right (along the $\mathrm{X}$ axis) and two units up (along the $\mathrm{Y}$ axis). The point $(-2,-1)$ is found by beginning at the origin and then moving two units to the left and one unit down. The points $(3,2)$ and $(-2,-1)$ are shown in Figure 2. It is useful to divide the plane into four quadrants. The first quadrant (quadrant I) is defined as the set of all of those points whose $\mathrm{X}$ and $\mathrm{Y}$ coordinates are both positive. The second quadrant (quadrant II) is the set of all points whose $\mathrm{X}$ coordinate is negative and whose $\mathrm{Y}$ coordinate is positive. Those points whose $\mathrm{X}$ coordinate and $\mathrm{Y}$ coordinate are both negative belong to the third quadrant (quadrant III); those whose $\mathrm{X}$ coordinate is positive and whose $\mathrm{Y}$ coordinate is negative belong to the fourth quadrant (quadrant IV). The four quadrants are also labelled in Figure 2.

In three dimensions it is necessary to introduce a third axis [12], the $\mathrm{Z}$ axis, which is perpendicular to both the $\mathrm{X}$ and $\mathrm{Y}$ axes. A point in three-dimensional space is identified by a set of three numbers. The point $(6,4,8)$, for example, is found by beginning at the origin and moving 6 units along the $\mathrm{X}$ axis (in the positive direction), 4 units along the $\mathrm{Y}$ axis, and 8 units along the $\mathrm{Z}$ axis. The $\mathrm{X}, \mathrm{Y}$ and $\mathrm{Z}$ axes, and the point $(6,4,8)$, are shown in Figure 3 . The JAEL system uses a threedimensional Cartesian coordinate system to describe the location of the bur.Because the bur is angled vertically downwards, the system described thus far is only able to make cuts perpendicular to the base of the model. In order to makecuts at different angles, the model to be sectioned is placed on a small, inclinable platform, which is itself placed on the movable horizontal platform. The inclinable platform is able to rotate the model about a vertical axis and to tilt the model about a horizontal axis. The inclinable platform is shown in Figure 4 . In the figure the model is oriented so that the horizontal axis about which the model tilts is parallel to the sagittal axis. Figures $5 \mathrm{a}$ and $5 \mathrm{~b}$ show the inclinable platform with malocclusion model placed onto the movable platform.

The movements of the dental bur holder, the movable platform and the inclinable platform are driven by bipolar stepper motors. These motors allow for high-precision positioning of the dental bur relative to the model. The operator controls the movements of the bur by means of a joystick. A high-definition microscope camera attached to the dental bur holder transmits images of the bur to the operator's computer screen. A light pointing in the same direction as the camera is also attached to the dental bur holder. The operator controls the position of the bur by looking at the image on the computer screen; no direct visual contact with the model is needed. This allows the operator to section the model remotely. Figure 6 shows the camera and light
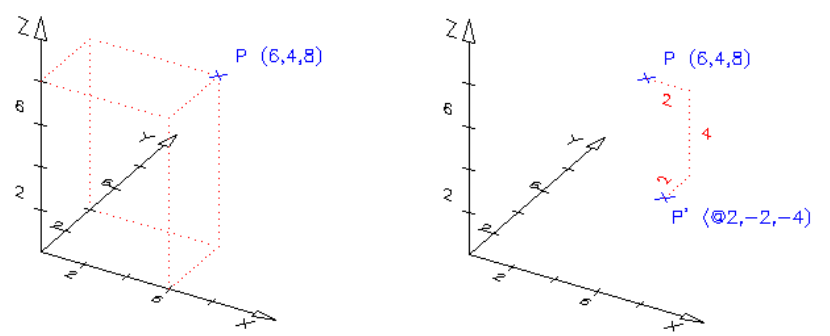

Figure 3: A three-dimensional Cartesian coordinate system with the point $(6,4,8)$ labelled.

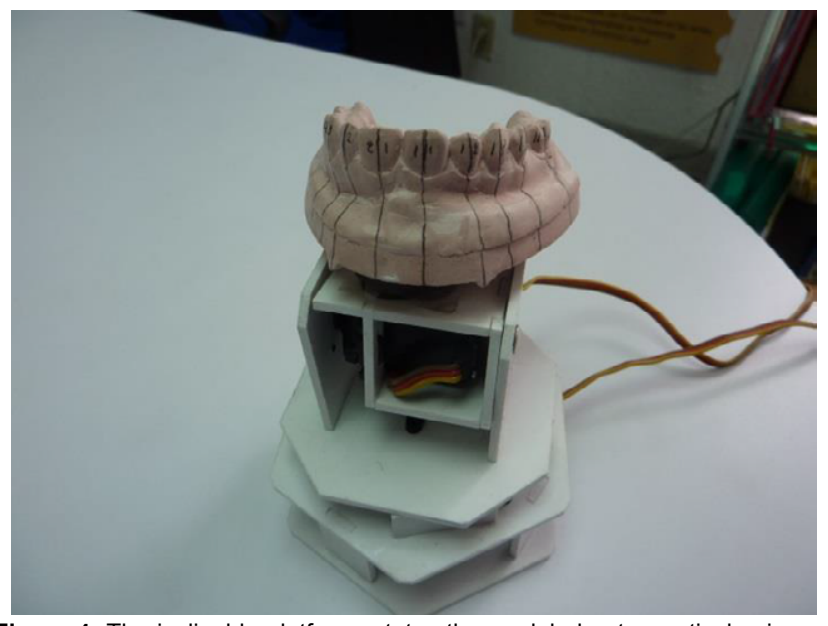

Figure 4: The inclinable platform rotates the model about a vertical axis and tilts the model about a horizontal axis. In this figure the model is oriented so that tilt axis is parallel to the sagittal axis. 
Citation: Gilbert A (2015) The JAEL System: A Joystick-Controlled Appliance for Exact Laboratory Procedures. J Comput Sci Syst Biol 8: $274-276$. doi:10.4172/jcsb. 1000167

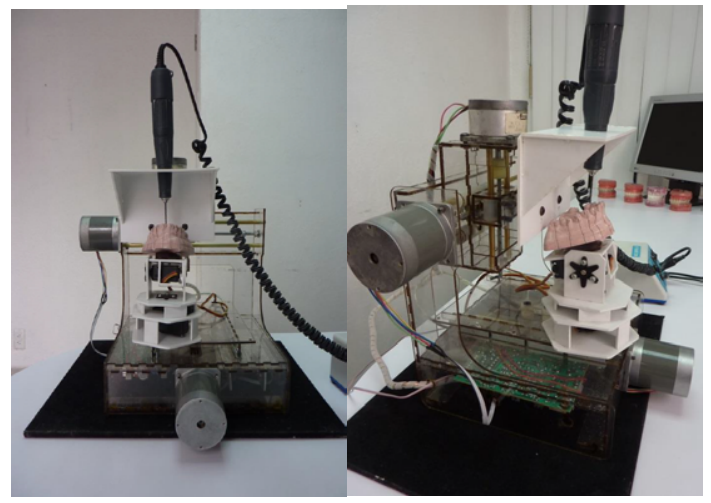

Figure $\mathbf{5 a}$ and $\mathbf{5 b}$ : Two different views of the inclinable platform with malocclusion model placed onto the movable platform.

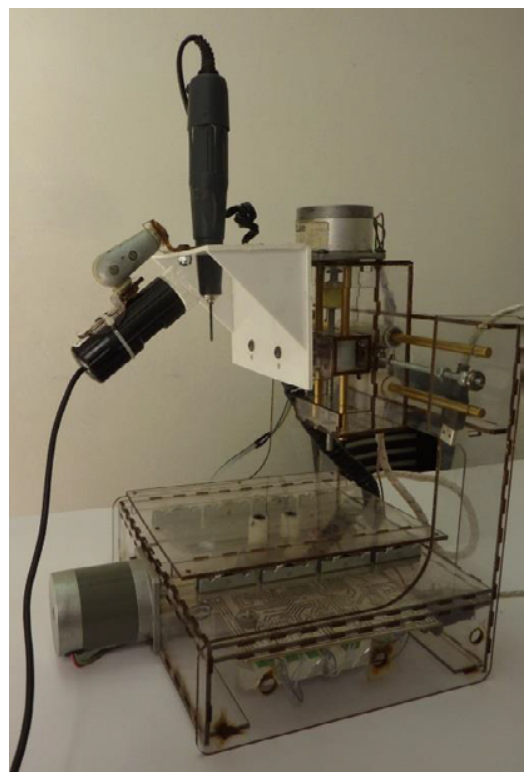

Figure 6: The microscope camera and light attached to the dental bur holder.

attached to the dental bur holder.

\section{A preliminary evaluation of the JAEL system}

One of the purposes of the JAEL system is to reduce the time required to section malocclusion models and to construct set-ups. To test whether use of the JAEL system does in fact reduce the time required to construct a set-up model, four orthodontic students and one orthodontic technician were each presented with a pair of identical malocclusion models and asked to section the models and then construct the set-up models. One of the malocclusion models were sectioned manually and the other using the JAEL system. In this preliminary evaluation the malocclusion models corresponded to simple non-extraction cases. Each participant was given his or her own individual case; the participants did not havemalocclusion models corresponding to the same cases. The participants had no prior training or experience with the JAEL system. The time required to construct the set-up models was recorded (Table 1). The average time to construct a set-up model manually was 4 hours and 53 minutes; the average time to construct a set-up model using the JAEL system was 2 hours and 52 minutes. This informal experiment clearly indicates that use of the

\begin{tabular}{|l|c|c|}
\hline \multirow{2}{*}{ Participant } & \multicolumn{2}{|c|}{ Time (hours: minutes) } \\
\cline { 2 - 3 } & Manual & JAEL \\
\hline Student & $5: 10$ & $3: 10$ \\
\hline Student & $5: 40$ & $3: 40$ \\
\hline Student & $4: 55$ & $2: 50$ \\
\hline Student & $5: 20$ & $3: 35$ \\
\hline Technician & $3: 20$ & $1: 05$ \\
\hline Mean & $4: 53$ & $2: 52$ \\
\hline
\end{tabular}

Table 1: The time taken by the five participants to construct a set-up manually and to construct a set-up using the JAEL system.

JAEL system significantly reduces the time required to construct a setup model.

\section{Conclusion}

The construction of set-up models is a common procedure that facilitates both diagnosis and treatment planning in surgical and non-surgical orthodontic cases as well as in the building of prothesic devices. One of the steps required in the construction of a set-up model -the sectioning of the malocclusion model-is a time-consuming and difficult procedure when carried out manually. Sectioning malocclusion models also produces a great quantity of dust, to which laboratory technicians may be exposed. The JAEL system presented here allows the technician to section malocclusion models remotely. The use of the system makes the process of sectioning malocclusion models quicker, safer and more precise, and reduces the time required to construct setup models. It is hoped that the system will be soon be available at a price affordable for solo practitioners, and become a valuable piece of laboratory equipment.

\section{References}

1. Bell WH (1992) Modern practice in orthognathic and reconstructive surgery, W. B. Saunders Co., Philadelphia.

2. Graber TM (1969) Current Orthodontic Concepts and Techniques, W.B Saunders Co., Philadelphia.

3. Proffit WR, White Jr. RP (1991) Surgical-Orthodontic Treatment, Mosby-Year Book, Inc., St. Louis.

4. Aguirre MJ (1984) Indirect bonding for lingual cases. J Clin Orthod 18: 565-569.

5. Hiro T, Fernando de la Iglesia, PuigdollersAndreu (1998) Resin Core Indirect Bonding System: Improvement of Lingual Orthodontics. J Japan Orthod Soc 57: 83-89.

6. Champagne M (1992) Reliability of measurements from photocopies of study models. J ClinOrthod 26: 648-650.

7. Macchi A, Carrafiello G, Cacciafesta V, Norcini A (2006) Three-dimensional digital modeling and setup. Am J OrthodDentofacialOrthop 129: 605-610.

8. Shellhart WC, Lange DW, Kluemper GT, Hicks EP, Kaplan AL (1995) Reliability of the Bolton tooth-size analysis when applied to crowded dentitions. Angle Orthod 65: 327-334.

9. Baumgaertel S, Palomo JM, Palomo L, Hans MG (2009) Reliability and accuracy of cone-beam computed tomography dental measurements. Am J Orthod Dentofacial Orthop 136: 19-25.

10. Blognese AM (1995)Técnica de set-up. SBO 2: 245-249.

11. Wolf S (1973)GuiaparamedicionesElectrónicas y Prácticas de laboratorio Traducido al español e impreso en México por Ed. Calypso, S. A. 1986, deltítulo original en inglés de la Ed. Prentice Hall.

12. Barrientos A, Peñin LF, Balaguer C, Aracil R (1998)Fundamentos de Robótica, Ed. McGraw-Hill// Interamericana de España, S.A.U. 